\title{
Study of air bubble dynamics in an air column using CFD
}

\author{
Corina Boncescu ${ }^{1, *}$, and Lăcrămioara Diana Robescu ${ }^{1}$ \\ ${ }^{1}$ University POLITEHNICA of Bucharest, Department of Hydraulics, Hydraulic Machinery and Environmental Engineering, 313 Splaiul \\ Independentei, Sector 6, 060042, Bucharest, Romania
}

\begin{abstract}
The energy used for biological process in a wastewater treatment plant depends on aeration equipment and hydraulic parameters in aeration tank. Gas bubbles flow into bioreactor determines an extra turbulence into the mixture. This paper presents the results obtained using the volume of fluid (VOF) mathematical model to determine the velocities generated by bubbles into an upward flow air-water mixture in a column of water. Also, it was identified vertexes center in the ascending air bubbles movement and the number and the diameter of the bubbles were determined. The theoretical results were compared to experimental and theoretical data from the literature and it was found a good correlation.
\end{abstract}

\section{Introduction}

Aeration is a key process in biological wastewater treatment. Its role is to supply the oxygen required to fulfill aerobic treatment processes. In activated sludge systems, aeration also ensures the required mixing velocity of the suspended particles, that means medium velocity $v_{m}>0.3 \mathrm{~m} / \mathrm{s}$ and homogenization of the wastewater-air-sludge mixture. Simulating the flow of gas bubbles in the aqueous environment is complex and has been the subject of numerous studies [1-4]. Oxygen transfer is performed at the interface of the two phases, air and water, represented by the surface of the gas bubbles. The uniform distribution of air bubbles and the production of small ones leads to an increase in oxygen mass transfer surface [5], avoiding the clogging of aeration systems, which is a major problem in many types of diffusers. Therefore, the distribution of dissolved oxygen concentration depends on the tank geometry, dispersion coefficient and gas velocity. These characteristics determine the required gas flow, respectively the efficiency of the aeration system. The two parameters depend on the biphasic mixture flowing regime and contribute to a homogeneous dispersion of water-air- sludge [6]. The air flowrate transferred in water is strongly influenced by the air-water interface.

Over time, mathematical models describing the flow and dispersion of gas bubbles have been performed using the Euler-Euler method [7-9] or the Euler-Lagrange method [10-11] for different geometries of the aeration tank. Simulations in 2D and 3D domains were also performed in stationary or transient mode. Research shows that $2 \mathrm{D}$ stationary simulations provide accurate average flowrates [12-17].

Since 1980s, more research has been done on the physical properties of diffuser's membrane and bubble generation phenomena [18-21]. Researches has revealed that the interfacial area (a) can be determined experimentally by knowing the bubble size $\left(d_{b}\right)$, the frequency of its formation $\left(f_{b}\right)$ and the bubble velocity $\left(u_{b}\right)$. Also, some studies [22] have shown that regardless of the liquid phase there are three areas where the mass transfer coefficient kl falls: if $d_{b}<1.5 \mathrm{~mm}$ then $k_{l} \approx 10-4$ $\mathrm{m} / \mathrm{s}$, if $1.5 \mathrm{~mm}<d_{b}<3.5 \mathrm{~mm}, \mathrm{kl}$ increases with the increasing bubble diameter and for $d_{b}>3.5 \mathrm{~mm}, \mathrm{kl}$ remains constant and depends only on the active agent in the liquid [23].

To improve the biological treatment process it is necessary to understand in detail the formation and movement of air bubbles in the water. Research has begun by studying the oxygen transfer process to optimize active sludge processes through aeration, and found that the oxygen transfer efficiency increases when the bubble size decreases [24]. These included the study of the effects of the operating and geometrical variables on the bubble dispersion coefficient and the characteristic distribution velocity in the column diameter range of $0.10-2.5 \mathrm{~m}$, the superficial liquid velocity, $0.04-0.21 \mathrm{~m} / \mathrm{s}$ and the surface gas velocity of $0.41-3.16 \mathrm{~mm} / \mathrm{s}$ [25]. Numerical simulations study of the gas-liquid flow in the aeration tank, where the air was injected at the bottom of the tank through the aeration tube, have shown that the higher the velocity of aeration, the more vortex occurred that indicates a better oxygen diffusion [26]. If the water is replaced with a low-concentration polymer solution it has been shown that the bubble velocity rate increases as the volume increases. In trajectory analysis, smaller bubbles exhibit helical or zigzag motion and larger bubbles perform a spiral motion [27].

In this paper there are identified the gas bubbles size and velocities generated in water for different sizes of the air inlet nozzle in a water column, correlated with the degree of turbulence for each analyzed cases. The results have shown that swirl formation is an important factor in the transfer of oxygen from air to water.

\footnotetext{
* Corresponding author: corinai05@yahoo.com
} 


\section{Material and methods}

Numerical modeling domain is two-dimensional, with the width $l=0.10 \mathrm{~m}$ and the height $H=0.20 \mathrm{~m}$. Gas velocity values are between $v_{g}=0.10-0.5 \mathrm{~m} / \mathrm{s}$ and the diameter of the air inlet nozzles $d_{0}=0.5-1.5 \mathrm{~mm}$. Numerical simulations are performed with the FLUENT program for steady state laminar flow. The mathematical model used to determine generated and induced velocity in the air-water mixture flow by upward movement of air bubble is VOF model.

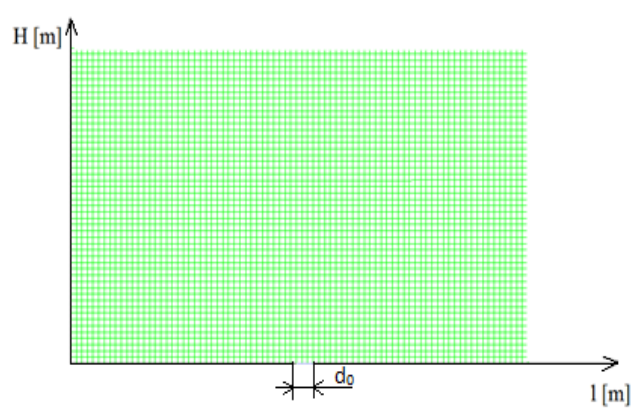

Fig. 1. Modeling domain and integration network.

The equations used in this model are continuity equation (Eq. 1) and moment equation (Eq. 2). The pressure is calculated with "body force weighted" model and for the relationship between pressure and velocity is used PISO method (Pressure Implicit with Split Operator).

$\frac{\partial\left(C_{g} \cdot \rho_{g}\right)}{\partial t}+\operatorname{div}\left(C_{g} \cdot \rho_{g} \cdot v_{g}\right)=0$
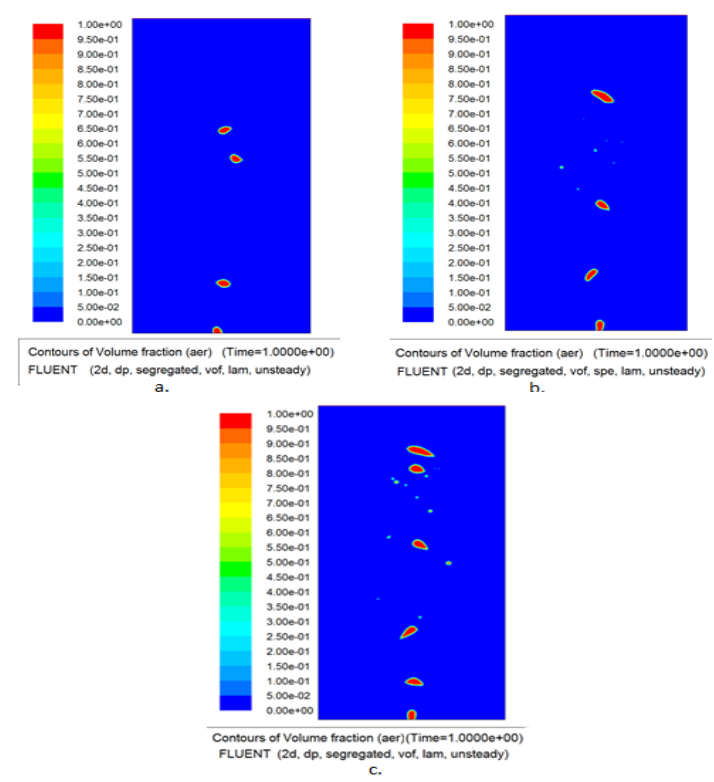

Fig. 2. Representation of the air volume fraction for the diameter of the nozzle $d_{0}=0.5 \mathrm{~mm}$ and velocity $v_{g, 0}=0.17 \mathrm{~m} / \mathrm{s}$ (a), $v_{g, 0}=0.25 \mathrm{~m} / \mathrm{s}(\mathrm{b}), v_{g, 0}=0.4 \mathrm{~m} / \mathrm{s}$ (c).

$$
\begin{aligned}
\frac{\partial\left(\rho_{m} \cdot v_{m}\right)}{\partial t}+\operatorname{div} & \left(\rho_{m} \cdot v_{m} \cdot v_{m}\right)= \\
= & -\operatorname{gradp}_{m}+\Delta \tau+\rho_{m} \cdot g+F
\end{aligned}
$$

where $C_{g}$ - the volumetric concentration of air; $\rho g$ density of air; $v_{g}$-air velocities; $v_{m}$ - is the average velocity vector of the mixture; $\rho_{m}-$ density of the mixture; $p_{m}$-pressure of the mixture; $\tau$ - the tangential effort; $g$ - gravitational acceleration; $F$-term that includes superficial tension.

In this paper it is considered the following calculation assumptions: the initial flow rate of the water is $v_{l, 0}=0 \mathrm{~m} / \mathrm{s}$; the flow is unsteady state due to the variation in time of the bubble gas velocity; flow is done at small Reynolds numbers; the coefficient of superficial stress $\sigma$ is constant; gravitational acceleration is negative due to the upward movement.

For analyzed cases it is considered three nozzle diameters $(0.5 \mathrm{~mm}, 1 \mathrm{~mm}$ and $1.5 \mathrm{~mm})$ and three initial air intake velocity $(0.17 \mathrm{~m} / \mathrm{s}, 0.25 \mathrm{~m} / \mathrm{s}$ and $0,40 \mathrm{~m} / \mathrm{s})$. Time step used is $0.001 \mathrm{~s}$, with a 1000 -step modeling.

\section{Results and discussion}

The first numerical simulations are made for the size of the nozzle $d_{0}=0.5 \mathrm{~mm}$. For velocity $v_{g}=0.17 \mathrm{~m} / \mathrm{s}$, the air bubbles have spherical shape of about $1 \mathrm{~mm}$ in diameter (Fig. 2.a ) and generate low-velocity in water, with small and impact less whirlwinds (Fig. 3.a). As the air velocity is increased at $v_{g}=0.25 \mathrm{~m} / \mathrm{s}$, the bubbles begin to deform from the spherical shape (Fig. 2.b), and the velocity generated in the mixture increased to maximum values of $0.41-0.43 \mathrm{~m} / \mathrm{s}$ (Fig. 3.b). Also, the degree of turbulence increase due to the velocity variation on the vertical of the tank.
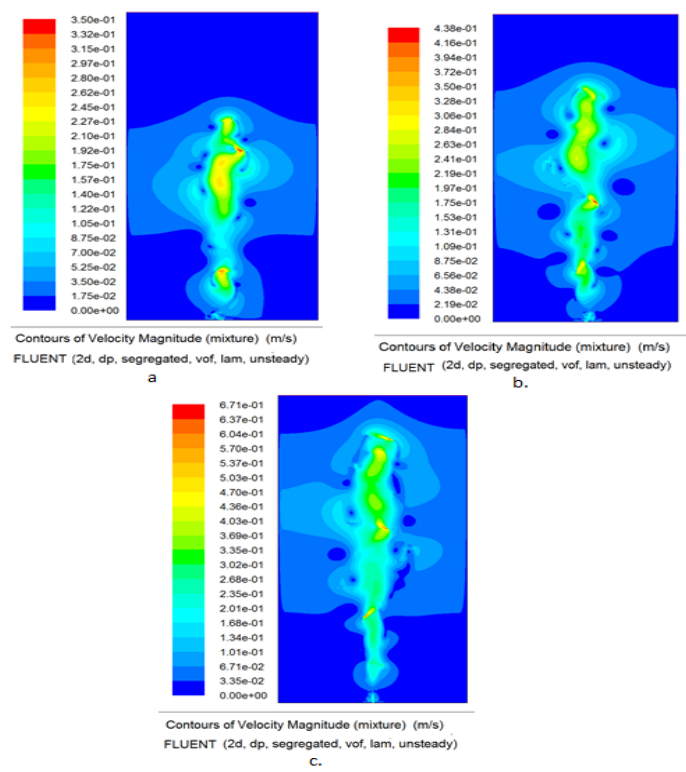

Fig. 3. Representation of the mixture contours of velocity for the diameter of the nozzle $d_{0}=0.5 \mathrm{~mm}$ and velocity $v_{g, 0}=0.17 \mathrm{~m} / \mathrm{s}(\mathrm{a}), v_{g, 0}=0.25 \mathrm{~m} / \mathrm{s}(\mathrm{b}), v_{g, 0}=0.4 \mathrm{~m} / \mathrm{s}$ (c). 
The air volume fraction and velocity spectrum generated and induced for $\mathrm{vg}=0.4 \mathrm{~m} / \mathrm{s}$ are shown in Fig. 2.c and Fig. 3.c respectively. Due to the increase in the diameter of the bubbles obtained, they change the shape and the phenomenon of bubble fractionation occurs.

Similar to the previous simulations, for the case of the nozzle diameter $\mathrm{d} 0=1 \mathrm{~mm}$, the same aspects are observed regarding the size of the gas bubbles, its shape, the occurrence of the coalescence phenomenon and the formation of the masses of air with significant impact on the oxygen transfer process in water.

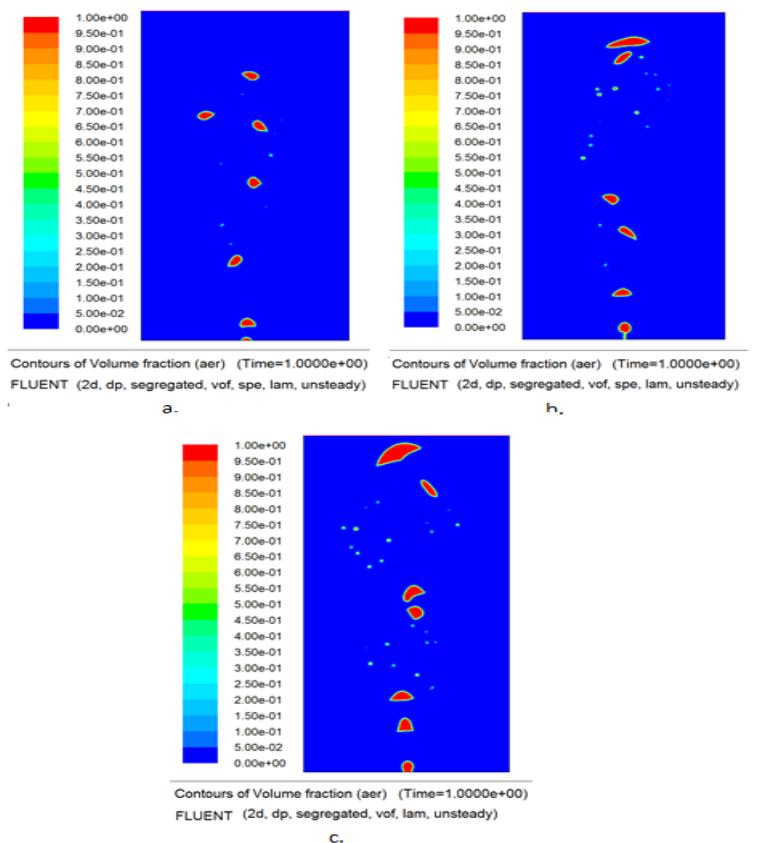

Fig. 4. Representation of the air volume fraction for the diameter of the nozzle $d_{0}=1 \mathrm{~mm}$ and velocity $v_{g, 0}=0.17 \mathrm{~m} / \mathrm{s}$ (a), $v_{g, 0}=0.25 \mathrm{~m} / \mathrm{s}(\mathrm{b}), v_{g, 0}=0.4 \mathrm{~m} / \mathrm{s}$ (c).

For gas velocity $v_{g, 0}=0.17 \mathrm{~m} / \mathrm{s}$, the obtained air bubbles spread on a larger surface with a slightly increased diameter of up to $4 \mathrm{~mm}$, favoring the transfer of oxygen (Fig. 4.a). However, the induced velocity is less than the velocity required to achieve the proper mixture flow, namely $0.30 \mathrm{~m} / \mathrm{s}$ (Fig. $5 . \mathrm{a}$ ).

At the air velocity $v_{g, 0}=0,25 \mathrm{~m}$ there are no essential changes but the bubbles are relatively larger (Fig. 4.b) and the velocities generated and induced in the mass of water increase (Fig. 5.b) . At the air velocity $v_{g, 0}=0.40$ $\mathrm{m} / \mathrm{s}$, the shape of the bubbles changed essentially (Fig. 4.c) and the maximum velocity value decrease from 0.75 $\mathrm{m} / \mathrm{s}$ to $0.57 \mathrm{~m} / \mathrm{s}$ (Fig. 5.c).

The notable difference for the diameter of the nozzle $d_{0}=1.5 \mathrm{~mm}$ and $v_{g, 0}=0.17 \mathrm{~m} / \mathrm{s}$ is that the size of the bubbles increases to $12-13 \mathrm{~mm}$ (Figure 6.a). The average velocity is maintained at $0.15 \mathrm{~m} / \mathrm{s}$ and there is movement generated in the whole water (Fig. 7.a). The swirl formation in the air inlet area occurs at the air intake velocity $\mathrm{v}_{\mathrm{g}, 0}=0.25 \mathrm{~m} / \mathrm{s}$. The generated and induced velocity in the water increases up to $0.7 \mathrm{~m} / \mathrm{s}$ (Fig. 7.b) and the smallest gas bubbles are $13 \mathrm{~mm}$ in size (Fig. 6.b). This size causes an increase in the velocity of the gas bubble and the decrease of oxygen transfer from air to water. In the case of $\mathrm{v}_{\mathrm{g}, 0}=0.40 \mathrm{~m} / \mathrm{s}$, the oxygen transfer surface decreases due to the fact that only masses of air are formed from which small bubbles are then separated (Fig. 6.c). Due to the high velocity up to $0.9-1.3 \mathrm{~m} / \mathrm{s}$, a downward movement occurs, which increases the degree of turbulence (Fig. 7.c).
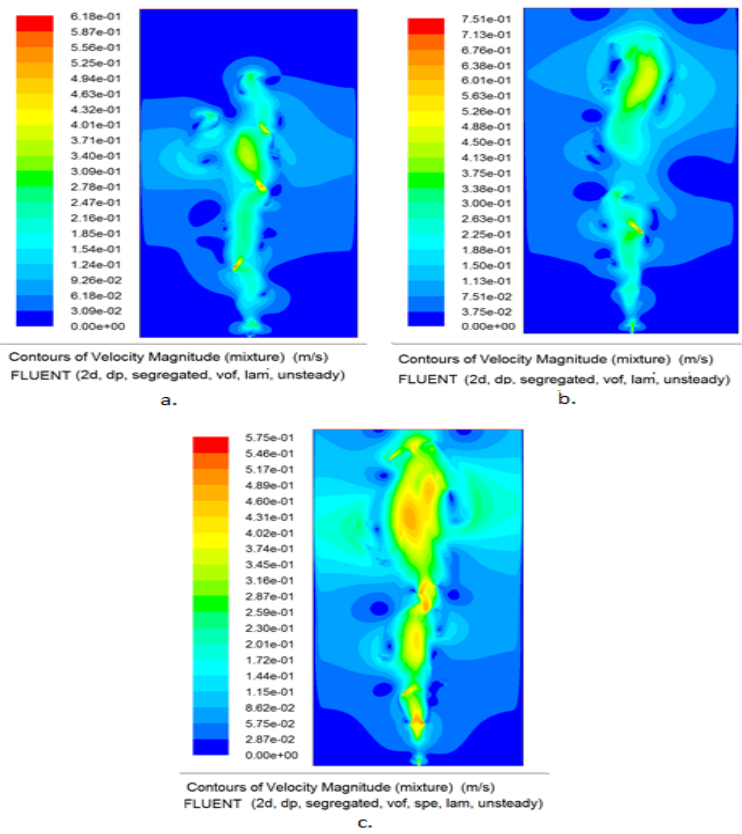

Fig. 5. Representation of the mixture contours of velocity for the diameter of the nozzle $d_{0}=1 \mathrm{~mm}$ and velocity $v_{g, 0}=0.17$ $\mathrm{m} / \mathrm{s}(\mathrm{a}), v_{g, 0}=0.25 \mathrm{~m} / \mathrm{s}(\mathrm{b}), v_{g, 0}=0.4 \mathrm{~m} / \mathrm{s}(\mathrm{c})$.
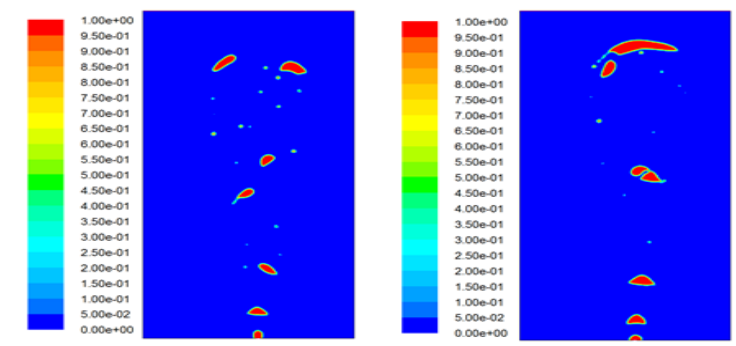

Contours of Volume fraction (aer) (Time=1.0000e+00) Contours of Volume fraction (aer) (Time $1.00000+00)$ FLUENT (2d, dp, segregated, vof, spe, lam, unsteady) FLUENT (2d, dp, segregated, vof, lam, unsteady)
b.

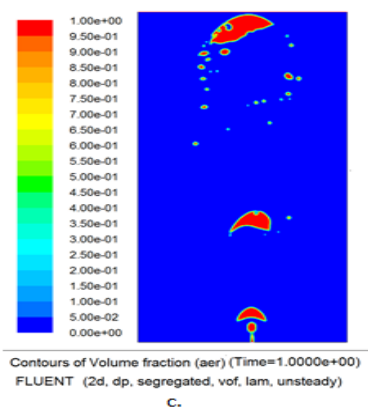

Fig. 6. Representation of the air volume fraction for the diameter of the nozzle $d_{0}=1.5 \mathrm{~mm}$ and velocity $v_{g, 0}=0.17 \mathrm{~m} / \mathrm{s}$ (a), $v_{g, 0}=0.25 \mathrm{~m} / \mathrm{s}(\mathrm{b}), v_{g, 0}=0.4 \mathrm{~m} / \mathrm{s}$ (c). 


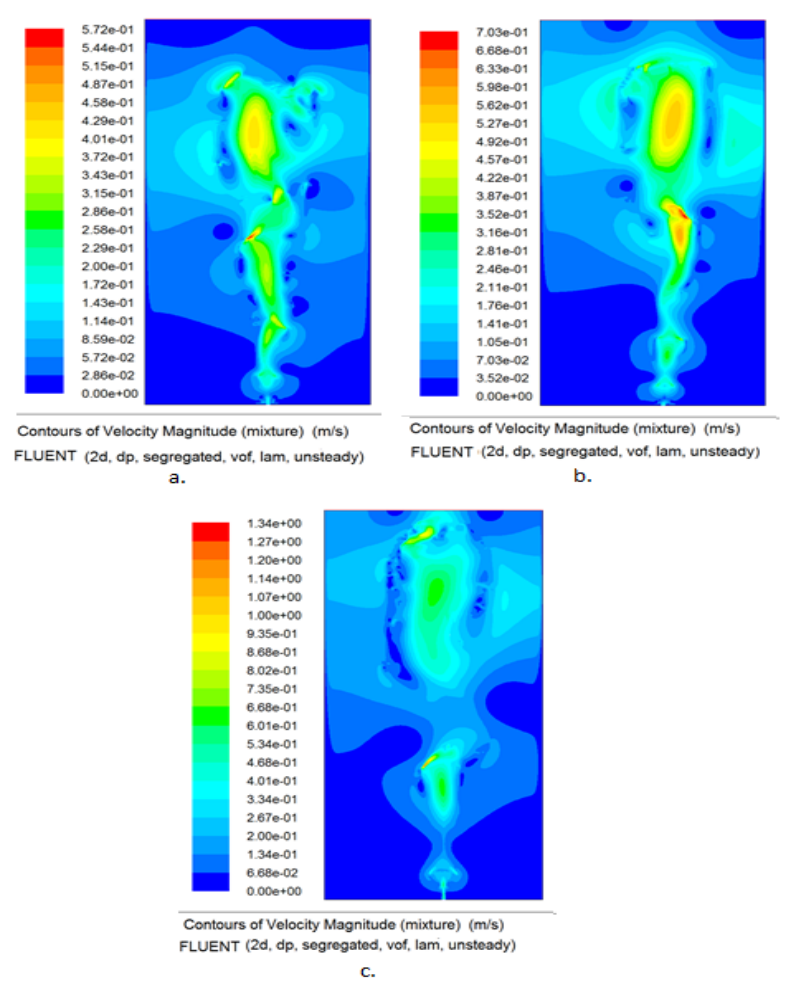

Fig. 7. Representation of the mixture contours of velocity for the diameter of the nozzle $d_{0}=1.5 \mathrm{~mm}$ and velocity $v_{g, 0}=0.17$ $\mathrm{m} / \mathrm{s}(\mathrm{a}), v_{g, 0}=0.25 \mathrm{~m} / \mathrm{s}(\mathrm{b}), v_{g, 0}=0.4 \mathrm{~m} / \mathrm{s}(\mathrm{c})$.

Table 1 presents the values obtained from mathematical simulations for the analyzed cases. It can be noticed that as the diameter of the air inlet increases, the velocity generated in the mass of water and the

Table 1. Results obtained from mathematical simulations for the three analyzed cases $d_{0}=0.5 \mathrm{~mm}, d_{0}=1 \mathrm{~mm}$ and $d_{0}=1.5 \mathrm{~mm}$.

\begin{tabular}{|c|c|c|c|c|c|}
\hline \multirow{2}{*}{$\mathrm{d}_{0}[\mathrm{~mm}]$} & $\mathrm{v}_{0}[\mathrm{~m} / \mathrm{s}]$ & No. of bubble & $\mathrm{d}_{\mathrm{b}}[\mathrm{mm}]$ & $\mathrm{v}_{\mathrm{m}, \mathrm{max}}[\mathrm{m} / \mathrm{s}]$ & No. of vertex \\
\hline \multirow{3}{*}{0.5} & 0.17 & 4 & $0.6-0.8$ & 0.35 & $7-9$ \\
\cline { 2 - 6 } & 0.25 & 4 & $0.9-1.5$ & 0.43 & $10-12$ \\
\cline { 2 - 6 } & 0.4 & 6 & $1.7-2$ & 0.67 & $10-11$ \\
\hline \multirow{3}{*}{1} & 0.17 & 6 & $2-3$ & 0.61 & $14-16$ \\
\cline { 2 - 6 } & 0.25 & 6 & $3-5$ & 0.75 & $17-17$ \\
\hline \multirow{3}{*}{1.5} & 0.4 & 7 & $5-7$ & 0.57 & $10-12$ \\
\cline { 2 - 6 } & 0.17 & 6 & $10-13$ & 0.57 & $11-13$ \\
\hline
\end{tabular}

As the diameter of the nozzle increased to $1 \mathrm{~mm}$, bubbly flow was obtained up to a gas pressure of 0.2 bar. The bubbles size varied between 5-9 $\mathrm{mm}$. An increase in pressure up to 0.6 bar caused a vertex in the air inlet area at a height of $15-20 \mathrm{~cm}$, which does not allow the formation of bubbles. With a pressure increase up to 0.8 bar, it appears as a jet of air from which small air bubbles break out. Due to the very high velocity they are moved to the wall area and driven in the downward movement.

For the diameter of the nozzle $1.5 \mathrm{~mm}$, the impact of air pressure on gas bubbles is lower. The required turbulence is increased. Also, the gas bubble also increases this, causing a decrease in the quantity of oxygen transferred from the air into the water.

For the validation of the mathematical model, an experimental installation is made in Laboratory of Dynamics of Multiphase Flow, Faculty of Power Engineering, University POLITEHNICA of Bucharest, for visualizing the movement of the air bubbles for the 3 analyzed cases. The experimental installation consists of a parallelepiped shaped thank with a height of $1 \mathrm{~m}$ and a width of $0.2 \mathrm{~m}$. At the bottom there is a plate on which there are nozzles with diameter of $0.5 \mathrm{~mm}, 1 \mathrm{~mm}$ and 1.5 $\mathrm{mm}$ respectively. The air is supplied by a compressor and the water column is kept in the steady state regime. The air pressure is measured with a metal pressure gauge and during experiments it varies between $0.05-0.8$ bar. The following parameters are measured: the velocity of the gas bubble, the diameter of the gas bubble, the diameter of the nozzles and the area of formation of the gas vortices. To determine the velocity of the gas bubble, a timer was used to measure as long as the bubble had passed the height of the water column.

For the diameter of the nozzle of $0.5 \mathrm{~mm}$, a bubbly flow regime was observed from air pressure between 0.05 bar and 0.1 bar and the diameter of the gas bubbles varied between 1-2 $\mathrm{mm}$. As the pressure increased, the phenomenon of coalescence occurred, with an impact on the interphase area through which the transfer of oxygen from air into water occurred. For the pressure over 0.15 bar, vertex appeared, which caused the turbulent flow regime. 
Comparing the values obtained for the gas bubble diameter following the experimental researches with those obtained by mathematical modelling, it was identify the situations for which similar results have been obtained. The comparative results are shown in Table 2.

Table 2. Comparison of experimental results with mathematical modelling.

\begin{tabular}{|c|c|c|c|c|c|}
\hline \multirow{2}{*}{$\mathrm{d}_{0}[\mathrm{~mm}]$} & \multirow{2}{*}{$\mathrm{d}_{\mathrm{b}}[\mathrm{mm}]$} & \multicolumn{3}{|c|}{ Mathematical modelling } & \multirow{2}{*}{$\begin{array}{c}\text { Experimental research } \\
\mathrm{p}[\mathrm{bar}]\end{array}$} \\
\hline & & $\mathrm{v}_{0}[\mathrm{~m} / \mathrm{s}]$ & $\mathrm{V}_{\mathrm{m}, \max }[\mathrm{m} / \mathrm{s}]$ & No. of vertex & \\
\hline \multirow{2}{*}{0.5} & \multirow{2}{*}{$1-2$} & 0.25 & 0.43 & $10-12$ & \multirow{2}{*}{$0.05-0.1$} \\
\hline & & 0.4 & 0.67 & $10-11$ & \\
\hline 1 & $5-9$ & 0.4 & 0.59 & $17-19$ & $0.1-0.2$ \\
\hline \multirow{3}{*}{1.5} & \multirow{2}{*}{$10-15$} & 0.17 & 0.57 & $10-12$ & \multirow{2}{*}{$0.15-0.45$} \\
\hline & & 0.25 & 0.70 & $11-13$ & \\
\hline & $>30$ & 0.4 & 1.34 & Increased turbulence & $>0.45$ \\
\hline
\end{tabular}

\section{Conclusions}

Mathematical modeling and simulations were performed using FLUENT, in unsteady state flow, for three values of the air inlet nozzle diameter, $0.5 \mathrm{~mm}, 1 \mathrm{~mm}$ and 1.5 $\mathrm{mm}$ respectively. The gas inlet velocity ranged from 0.17 to $0.5 \mathrm{~m} / \mathrm{s}$.

According to the obtained numerical results, it can be stated that from the point of view of the bubble formation, the best solution corresponds to a diameter of $d_{0}=0.5 \mathrm{~mm}$, because small amounts of spherical air bubbles appear, with large contact area. In the case of the nozzle with diameter $d_{0}=1 \mathrm{~mm}$, the velocity generated by the movement of the air bubbles in the water mass leads to a flow regime favorable to the transfer of oxygen from air into water. Increasing the diameter of the nozzle at $d_{0}=1.5 \mathrm{~mm}$ is unfavorable from both points of view: the gas bubbles obtained are too large $\left(d_{b}\right.$ $>30 \mathrm{~mm}$ ) so that the specific air-water transfer surface decreases and the velocities generated in the biphasic fluid system prevents intimate contact between air and water.

As a result the nozzle with diameter of $0.1 \mathrm{~mm}$ and a gas velocity of $0.17 \mathrm{~m} / \mathrm{s}$ gives small spherical bubbles $d_{b}$ $<10 \mathrm{~mm}$ which provide high oxygen transfer and optimal velocity for the biphasic mixture flow. Numerical results show a good correlation with experimental ones.

This work is supported by MEN-UEFISCDI within the framework of National Plan for Research, Development and Innovation 2007-2014, Partnerships in Priority Domains Program, PN-II-PT-PCCA-2013-4-1649, project no. 274/2014.

\section{References}

1. S. Gillota, S. Capela-Marsala, M. Roustanb, A. He'duita, Water Res., 39, 1379-1387, (2005)
2. M. Mart, F. J Montes, M. A Galan, Chem. Eng. J., 128, 21-32; (2007)

3. M. E. C. Oliveira, A. S. Franca, Int. J. Heat Mass Transfer, 25, 853-862(1998)

4. M. E. C Oliveira, A. S. Franca, Int. J. Heat Mass Transfer, 25, 853-862(1998)

5. R. G. Rice, N. B. Lakhani, Chem. Eng. Commun., 24, 215-234, (1983)

6. J Florea, D. Robescu, T. Petrovici, D. Stamatoiu Dynamics of polyphase fluids and its technical applications (Dinamica fluidelor polifazice şi aplicaţiile ei tehnice), Ed. Tehnica, Bucharest (1987)

7. H.A. Jakobsen, H. Lindborg, C.A. Dorao, Ind. Eng. Chem. Res., 44, 5107-5151,(2005)

8. D. Pfleger, S. Becker, Chem. Eng. Sci., 56, 17371747, (2001)

9. A. Sokolichin, G. Eigenberger, A. Lapin, A.I.Ch.E. Journal 50,, (2004)

10. S. Lain, D. Bröder, M. Sommerfeld, M.F. Göz, Int. J. Multiphase Flow, 28, 1381-1407, (2002)

11. A. Lapin, A. Lübbert, Chem. Eng. Sci., 49, 36613674, (1994)

12. D. Bixio, G. Parmentier, D. Rousseau, F. Verdonck, J. Meirlaen, P.A. Vanrolleghem, C. Thoeye, Wat. Sci. Tech., 46 (4-5), 301-307, (2002)

13. L. Benedetti, B. De Baets, I. Nopens, P.A. Vanrolleghem, Environ. Modell. Softw., 25, 616621 (2010)

14. A. Rivas, I. Irizar, E. Ayesa, Environ. Modell. Softw., 23, 35-450 (2008)

15. Ayesa, A. De la Sota, P. Grau, J.M. Sagarna, A. Salterain, J. Suescun, Wat. Sci. Tech., 53 (4-5) 193201, (2006) 
16. M. Yong, P. Yongzhen, U. Jeppsson, Control Eng. Pract., 14 ,1269-1278, (2006)

17. X. Flores-Alsina, I. Rodríguez-Roda, G. Sin, K. Gernaey, Wat. Res., 42, 4485-4497, (2008)

18. F. Bischof, M. Sommerfeld, Tsukuba, Japan (1991)

19. K. Loubière, G. Hébrard, Chem. Eng. Sci., 58, 135148, (2003)

20. R. G. Rice, S. W. Howell, AIChE Journal, 32, 13771382, (1986)

21. P. Painmanakul, K. Loubière, G. Hébrard, P., Buffière, Chem. Eng. Process., 43, 1347-1359, (2004)

22. P. Painmanakul, G. Hébrard, Chem. Eng. Res. Des., 86, 1207-1215, (2008)

23. R. Sardeing, P. Painmanakul G., Hébrard, Chem. Eng. Sci., 61, 6249-6260, (2006)

24. Y. Fayolle, A. Cockx, S. Gillot, M. Roustan, A. Heduit, Chem. Eng. Sci., 62, 7163-7171, (2007);

25. S. K. Majumder, Chem. Eng. Sci., 63, 3160-3170 (2008)

26. Y. Hu, Y. Guo, W. Zhu, B. Chen, International Conference on Mechanic Automation and Control Engineering, IEEE, (2010)

27. N. M. S. Hassan, M. M. K. Khan, M. G. Rasul, Australia, (2007) 